\title{
Caudal Block Versus Penile Block for Postoperative Analgesia in Children Undergoing Hypospadias Repair
}

\author{
Mohamed B. Al-Metwally ${ }^{1, *}$ MSc, Ezzat M. Al-Saudi ${ }^{2}$ MD, Ahmed M. Abo El Ata ${ }^{1}$ MD , \\ Medhat H. Allam ${ }^{2}$ MD
}

\section{*Corresponding Author: \\ Mohamed B. Al-Metwally mohamed.bhgat2013@gmail.com}

Received for publication July 1, 2020; Accepted October 2, 2020; Published online October 2, 2020.

Copyright 2020 The Authors published by Al-Azhar University, Faculty of Medicine, Cairo, Egypt. All rights reserved. This an openaccess article distributed under the legal terms, where it is permissible to download and share the work provided it is properly cited. The work cannot be changed in anyway or used commercially.

doi: 10.21608/aimj.2020.35550.128

${ }^{1}$ Anesthesia and Intensive Care Department, Faculty of Medicine, Al-Azhar University, Damietta, Egypt.

${ }^{2}$ Anesthesia and Intensive Care Department, Faculty of Medicine, Al-Azhar University, Assuit, Egypt.

\begin{abstract}
Background: Caudal block is recommended for analgesia during and after hypospadias repair operation of the penis in children.

Aim of work: Compare the effectiveness of caudal block vs. dorsal penile block in children undergoing hypospadias repair surgery with respect to postoperative analgesia and appeal for rescue analgesics during the first 24 hours.

Patient and Methods: The study was conducted on 40 male children, ASA I-II, 4-8 years of age undergoing hypospadias repair surgery under general anesthesia. Children were randomly classified into two groups: (Group P) (penile group=20 patients) received a penile block of $2 \mathrm{~mL}$ bupivacaine 0.25 per cent on each side, (Group C) (caudal block group $=20$ patients) with a caudal block of 0.25 per cent $(1 \mathrm{mg} / \mathrm{kg})$ bupivacaine. Postoperative pain assessment will be conducted by mCHEOPS Children's Hospital of Eastern Ontario Pain Scale (request for rescue analgesic and complete analgesic dosage (mg.).

Results: The PACU mCHEOPS pain score was lower in Group $\mathrm{C}$ at 2 hrs, 4 hrs and 6 hrs postoperative. Also, the time firstly needed for rescue analgesia was statistically significantly and lower in group C. The overall analgesic rescue requirement in Group $\mathrm{C}$ was also significantly lower.

Conclusion: $\mathrm{T}$ Caudal block tended to be more effective in lowering postoperative pain scores and decreasing the need for rescue analgesia.

Keywords: Caudal block; Penile block; Bupivacaine; Hypospadias repair.

Disclosure: The authors have no financial interest to declare in relation to the content of this article. The Article Processing Charge was paid for by the authors.

Authorship: All authors have a substantial contribution to the article.
\end{abstract}

\section{INTRODUCTION}

Pain is one of the most complicated, underdiagnosed, and untreated medical problems, particularly in children. The Current Joint Commission on Accreditation of Health Care Organization treats pain as a fifth vital sign and allows clinicians to measure pain regularly. Postoperative pain may result in an uncooperative and restless child. It is also better to delay the onset of pain and to reduce its presence. ${ }^{1}$

Regional anesthesia, combined with general anesthesia, is often used in children undergoing surgery. The benefits of this strategy are a simplified intraoperative pathway and reduced general

anesthetic requirements, quicker, easier waking up, and good pain relief in postoperatively. ${ }^{2}$

Certain benefits involve suppression of unwanted reflexes such as laryngospasm during operations, early ambulation, early hospital discharge, decreased need for non-narcotic analgesics after discharge, and a quicker return to the normally bright and alert state of the infant. Postoperative vomiting is less frequent during regional anaesthesia than when opiates are used for analgesia and early resumption of oral fluid intake is probable. ${ }^{3}$

One of the most powerful and widely practiced regional forms of pediatric anesthesia is a single-shot caudal tube. They are goodfor lower extremities, perineal and lower abdominal surgery.Caudal block is a fast and secure procedure that providesbetter patient comfort and better outcomes, and could also reduce anesthesia time. ${ }^{4}$

Penile blocks have been more usually used in pediatric patients as an alternative to general anesthesia in penile procedures such as circumcision, hypospadias reconstruction, urethral dilation and laser fulguration. This also gives the distal $2 / 3$ of the penis anesthesia. ${ }^{5}$ 
In this experiment, we were matched between the caudal block and the dorsal penile block in children undergoing hypospadias repair surgery to assess postoperative pain in terms of frequency, duration and need for rescue analgesia within the first 24 hours.

Aim of the study compares the caudal block and penile block in children undergoing hypospadias surgery with postoperative analgesia (intensity, length, request for rescue analgesia and total dose of analgesia).

\section{PATIENT AND MATERIALS}

This is a retrospective, randomized clinical research performed from October 2019 to May 2020 at the Department of Anesthesiology and Intensive Care of Al-Azhar University Hospitals (Damietta) after approval by the central ethics committee of the Damietta Faculty of Medicine, Al-Azhar University. 40 male children (ASA I or II) aged (4-8 years) undergoing hypospadias surgery among those at $\mathrm{Al}$ Azhar University Hospitals (Damietta) were included in this study after receiving informed and written consent from their parents.Any child with Suspected testicular torsion, below or above the age, ASA III or above, with muscle diseases, Coagulopathy,Presence of significant spinal defect, infection of the skin, or subcutaneous tissue at the site of injection was excluded from the study.

Procedures: Patients will be randomly assigned to one of two groups (20 patients in each group) using a computerized generator and sealed opaque envelopes. Group (P) undergoes a penile block and group (C) patients undergo a caudal block.

Group $(P)$ penile block $(n=20)$ : After the patient has been put in a supine position with exposed genitalia, the area will be sterilized with bovidone iodine solution and sterile wraps will be applied. Using a 27-g needle to lift the skin wheals at 2 and 10 o'clock levels, then gradually introduce the needle within the middle of each skin wheal. The needle is guided to the middle of the shaft deeplyforabout $0.5 \mathrm{~cm}$ or to the point where the lack of resistance is felt to indicate that the tip is within the Buck fascia. Aspirate to make sure that the needle is not in the blood vessel and gently inject about $2 \mathrm{~mL}$ of bupivacaine $0.25 \%$ on each side.

Group (C) caudal block ( $\mathrm{n}=20)$ : After the patient is positioned in the left side, the sacrococcygeal area is sterilized with bovidone iodine solution and sterile wraps are added.The sacral hiatus is localized and punctured with a needle before the ventral wall of the sacrum is reached, inclined before the lack of resistance due to the Dural puncture occurs, placing it horizontally and then advanced to the cephalad when sucking.Confirmation of correct placement of the normal hypodermic needle is done by injection of 1 to $2 \mathrm{ml}$ of air while a stethoscope is fixed over the lumbar vertebrae. If there is no formation of weal in the subcutaneous tissue, the anesthetic is injected bupivacaine $0.25 \%(1 \mathrm{mg} / \mathrm{kg})$ slowly with frequent aspirations during the injection.
Measurements: niap evitarepotsop fo tnemssessA deifidom gnisuChildren's Hospital Eastern Ontario Pain Scale(SPOEHCm) ${ }^{[6]}$ at 30 mins after full recovery then at 1,2,4,8,16 and 24hrs postoperatively

\begin{tabular}{|c|c|c|c|}
\hline $\begin{array}{c}\text { Scor } \\
\text { e }\end{array}$ & $\mathbf{0}$ & $\mathbf{1}$ & $\mathbf{2}$ \\
\hline Cry & No cry & Crying & Shout \\
\hline Facial & Smiling & Composed & Grimace \\
\hline Verbal & Positive & $\begin{array}{c}\text { non or another } \\
\text { complaint }\end{array}$ & $\begin{array}{c}\text { pain, } \\
\text { complaint }\end{array}$ \\
\hline Torso & Natural & $\begin{array}{c}\text { Shifting, tense, } \\
\text { upright }\end{array}$ & Restrained \\
\hline Legs & Natural & $\begin{array}{c}\text { kick, squirm, } \\
\text { drawn up }\end{array}$ & Restrained \\
\hline
\end{tabular}

Table 1: deifidomChildren's Hospital Eastern Ontario Pain Scale .(SPOEHCm)

Time for rescue analgesia: paracetamol $10 \mathrm{mg} / \mathrm{kg}$ will be given as rescue analgesia when CHEOPS score $\geq$ 5 . It will be repeated after 6 hours if necessary.

Time for the first dose and total dose of paracetamol (mg.)will be recorded upto 24Hrs.

sisylanA lacitsitatS: The findings were analyzed using SPSS (Statistics Kit of Social Sciences) version 23 (SPSS Inc., Chicago, IL , USA). The normally distributed data is seen in mean and standard deviations. Quantitative data were examined by the Kolmogorov Smirnov data normality test Independent sample t-test (student t-test) and U-test (Mann-Whitney U-test) were used for comparison between the two groups. Significant effects were considered when the $\mathrm{P}$ value was less than or equal to 0.05 .

\section{RESULTS}

As for demographic data such as age , sex , body weight, type and duration of surgery, there was no significant difference between the two groups (pvalue $>0.05$ ) as shown in (Table 2 ). 


\begin{tabular}{|c|c|c|c|c|}
\hline & $\begin{array}{l}\text { Penile block } \\
(\mathrm{n}=20)\end{array}$ & $\begin{array}{c}\text { Caudal block } \\
(\mathrm{n}=20)\end{array}$ & $\begin{array}{l}\text { Test of } \\
\text { Sig. }\end{array}$ & $P$ \\
\hline $\begin{array}{l}\text { Age (years) } \\
\text { Mean } \pm \text { SD }\end{array}$ & $6.05 \pm 1.36$ & $6.0 \pm 1.62$ & $\begin{array}{l}\mathrm{t}= \\
0.106\end{array}$ & 0.916 \\
\hline $\begin{array}{l}\text { Weight (kg) } \\
\text { Mean } \pm \text { SD. }\end{array}$ & $29.75 \pm 4.72$ & $29.60 \pm 5.71$ & $\begin{array}{l}\mathrm{t}= \\
0.091\end{array}$ & 0.928 \\
\hline $\begin{array}{l}\text { Height }(\mathrm{cm}) \\
\text { Mean } \pm \text { SD. }\end{array}$ & $113.9 \pm 9.22$ & $113.7 \pm 10.81$ & $\begin{array}{l}\mathrm{t}= \\
0.074\end{array}$ & 0.941 \\
\hline $\begin{array}{c}\text { BMI } \\
\text { Mean } \pm \text { SD. }\end{array}$ & $23.03 \pm 3.51$ & $22.82 \pm 2.30$ & $\begin{array}{l}t= \\
0.224\end{array}$ & 0.824 \\
\hline II ${ }^{\text {ASAI }}$ & $\begin{array}{c}15 \text { (75.0\%) } \\
5(25.0 \%)\end{array}$ & $\begin{array}{c}14 \text { (70.0\%) } \\
6(30.0 \%)\end{array}$ & 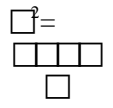 & 0.723 \\
\hline $\begin{array}{l}\text { Duration of } \\
\text { surgery (min.) } \\
\text { Mean } \pm \text { SD. }\end{array}$ & $\begin{array}{c}95.95 \pm \\
17.27\end{array}$ & $97.8 \pm 15.77$ & $\mathrm{t}=0$. & 0.725 \\
\hline
\end{tabular}

Table 2: Comparison between the two studied groups according to Demographic data.

With respect to postoperative pain level, the current study showed that postoperative Pain scores were significantly lower in the 2-hour C group (p-value > 0.05 ) and Pain scores were also significantly lower in the $\mathrm{C}$ group than in the 4-hour and 8-hour $\mathrm{P}$ groups (p-value $>0.001$ ) and there was no substantial difference between the 30-minute, 1-hour, 16-hour and 24-hour groups (Table 3).

\begin{tabular}{|r|c|c|c|c|}
\hline \multirow{2}{*}{$\begin{array}{c}\text { Post-Op } \\
\text { mCHEOPS } \\
\text { score }\end{array}$} & $\begin{array}{c}\text { Median } \\
\text { (Min. - Max.) }\end{array}$ & $\begin{array}{c}\text { Median } \\
\text { (Min. }- \\
\text { Max.) }\end{array}$ & $\begin{array}{c}\text { U- } \\
\text { test }\end{array}$ & $\begin{array}{c}\text { p- } \\
\text { value }\end{array}$ \\
\hline 30 min. & $2.0(1.0-2.0)$ & $2.0(0.0-2.0)$ & 188 & 0.705 \\
\hline 1 hr. & $2.0(1.0-2.0)$ & $2.0(1.0-2.0)$ & 190 & 0.739 \\
\hline $2 \mathrm{hr}$. & $3.0(2.0-5.0)$ & $3.0(1.0-3.0)$ & 105 & $0.007^{*}$ \\
\hline $4 \mathrm{hr}$. & $5.5(5.0-7.0)$ & $4.0(2.0-5.0)$ & 40 & $<0.001^{*}$ \\
\hline $8 \mathrm{hr}$. & $7.0(6.0-8.0)$ & $4.0(3.0-5.0)$ & 0 & $<0.001^{*}$ \\
\hline $16 \mathrm{hr}$. & $3.0(3.0-5.0)$ & $4.0(3.0-5.0)$ & 143 & 0.084 \\
\hline $24 \mathrm{hr}$. & $3.0(3.0-5.0)$ & $3.5(3.0-5.0)$ & 143 & 0.065 \\
\hline
\end{tabular}

Table 3: Intergroup comparison of postoperative mCHEOPS score.

he duration of rescue analgesia was significantly longer in the C-group compared to the P-group and the total dose of rescue analgesia was significantly higher in the P-group compared to the C-group (Table 4).

\begin{tabular}{|c|c|c|c|c|}
\hline Time of request rescue analgesia (min.) & $\begin{array}{c}\mathrm{P} \\
\text { Group }\end{array}$ & $\begin{array}{c}\mathrm{C} \\
\mathrm{Grou} \\
\mathrm{p}\end{array}$ & $\mathrm{t}$ & $\mathrm{P}$ \\
\hline Mean \pm SD. & $\begin{array}{c}75.05 \\
\pm 7.88\end{array}$ & $\begin{array}{c}121.0 \\
\pm \\
10.61\end{array}$ & $\begin{array}{c}15.53 \\
4\end{array}$ & $\begin{array}{c}<0.001 \\
*\end{array}$ \\
\hline Total doses of rescue analgesia (mg.) & \multicolumn{4}{|c|}{} \\
\hline Mean \pm SD. & $\begin{array}{c}434.0 \\
\pm 36.0 \\
1\end{array}$ & $\begin{array}{c}178.8 \\
\pm \\
16.84\end{array}$ & $\begin{array}{c}28.70 \\
6\end{array}$ & $\begin{array}{c}<0.001 \\
\text { (n) }\end{array}$ \\
\hline
\end{tabular}

T; t-test and *; for significant.

Table 4: Intergroup comparison of time of request of rescue analgesia and time of rescue analgesia.

\section{DISCUSSION}

This randomized study was designed to compare penile block and caudal block for hypospadias repair to show which of them is stronger in terms of effectiveness, pain management, and complications.

Forty children were randomly divided into two groups, each of which consisted of 20 patients in Cgroup, in which patients received caudal block and Pgroup, in which patients received penile block.

In the present study, a distinction was made between caudal and penile block with respect to postoperative pain score, rescue analgesia time and total analgesia dose. The current study discovered postoperative Pain scores were significantly lower in the 2-hour caudal group (p-value $>0.05$ ) and Pain scores were also significantly lower in the caudal group than in the 4-hour penile group. And 8 hr. (p-value > 0.001) and there was no substantial difference between the two classes of 30 min., 1 hr., 16 hr. and $24 \mathrm{hr}$.

The duration of rescue analgesia was significantly longer in the caudal group compared to the penile group, and the average dose of rescue analgesia was much higher in the penile group compared to the caudal group.

In agreement with our work Yasser A. Ragheb et al.,2018 ${ }^{[7]}$ The Faces pain level was found to be substantially lower in the Caudal Group at $2 \mathrm{H}, 4 \mathrm{H}$ and $6 \mathrm{H}$ postoperative ( $\mathrm{p}$-value $<0.05$ ) and the length of the block ranged from 1-5 hours in Penile Group and 1-10 hours in Caudal Group, with mean values of $2.57 \pm 1.10$ hours and $6.07 \pm 2.10$ hours respectively. A contrast between the two groups showed that there was a statistical change (p-value < 0.05 ) in the length of the block in the Caudal Group.

Also, they found that 11 patients (36.7\%) needed rescue analgesia while in Caudal Group, 3 patients (10\%) needed rescue analgesia, There was also a substantial increase ( $\mathrm{p}$-value $<0.05)$ in the need for rescue analgesia in the Penile Community.

And Canakci E et al.,2017 ${ }^{[8]}$ who compared three different techniques of preventive analgesia (Caudal, dorsal penile blocks and subcutaneous morphine) based on duration and quality of postoperative analgesia prior to circumcision in 60 male children 612 years of age, C-group patients received 0.25 per cent bupivacaine at a dose of $1 \mathrm{mg} / \mathrm{kg}$ with volume of $0.50 \mathrm{ml} / \mathrm{kg}$. Those in Group M received $100 \mathrm{mcg}$ / $\mathrm{kg}$ of subcutaneous morphine. Patients in the DP community had a penile block of $1 \mathrm{mg} / \mathrm{kg}$ bupivacaine of $0.25 \%$.They concluded that caudal block decrease postoperative pain measured by CHEOPS scores 1st, 6th,12th, 24th postoperative more than the penile block, and administration of subcutaneous morphine ( $\mathrm{p}$-value $<0.05$ ).

OncontraryAshrey and Bosat, $2014^{[2]}$ The FLACC pain scores were found to be highly lower in Group $\mathrm{P}$ compared to Group C $(\mathrm{P}<0.05)$.

Also, the time required for analgesia at first was significantly lower $(\mathrm{P}<0.05)$ in Group $\mathrm{P}$ relative to Group C. The overall need of analgesia was significantly lower $(\mathrm{P}<0.05)$ in Group $\mathrm{P}$ relative to 
Group C. They concluded that single-injection penile block is betterthan caudal epidural block for postoperative pain relief in children undergoing penile surgery.

Kundra P et al., $2013^{[9]}$ Compared the penile and caudal blocksas regard to the quality of analgesia after hypospadias surgeryon 54 children. P (penile blockn=27) and $C$ (caudal blockn=27) respectively. The level of analgesia was measured using a visual analog scale (VAS) score. In contrast to the results of the present report,In group $\mathrm{P}$, lower mean VAS scores from $30 \mathrm{~min}$ after surgery to $3^{\text {rd }}$ day and the length of analgesia was highly longer (82 min) relative to caudal. Researchers found that the penile block had better quality of analgesia than caudal in children undergoing hypospadias repair. That difference could be a result of using different tools of assessment of pain.

\section{CONCLUSION}

The use of either penile or caudal blocks in children undergoing penile surgery is effective in postoperative analgesia. The caudal block appeared to be more efficient in lowering postoperative pain scores and decreasing the need for rescue analgesia by prolonging the length of the block.

\section{REFERENCES}

1. Goyal V, Kubre J, Radhakrishnan K. Dexmedetomidine as an adjuvant to bupivacaine in caudal analgesia in children. Anesth Essays Res. 2016;10(2):227-7.

2. Ashrey E, Bosat B. Single-injection penile block versus caudal block in penile pediatric surgery. Ain-Shams J Anaesthesiol. 2014 ;7(3):428.doi:10.4103/1687-7934.139588
3. Ahmed, Ammar AS, Ismail AHM. Caudal versus spinal anesthesia in children undergoing lower abdominal operations. Menoufia Med $\mathrm{J}$. 2018;31(1):87. doi:10.4103/MMJ.MMJ_637_16

4. Ponde V. Recent trends in paediatric regional anaesthesia. Indian J Anaesth. 2019;63(9):746. doi:10.4103/ija.IJA_502_19

5. Panda A, Bajwa SJS, Sen S, Parmar SS. Penile block for paediatric urological surgery: A comparative evaluation with general anaesthesia. Indian J Urol. 2011;27(4):457-64. doi:10.4103/0970-1591.91432

6. Akatsuka M, Murouchi T, Arakawa J, Yamakage M. Ultrasound-guided para-umbilical block: a pediatric case. JA Clin Reports. 2017;3(1):33. doi:10.1186/s40981-017-0105-6

7. Yasser A. Ragheb, M.D. Salma E. Kandil, M.Sc., Ismaiel, M.D. SA. Prospective Randomized Controlled Study Comparing Caudal Block versus Dorsal Penile Nerve Block as Postoperative Analgesia in Children Presented for Penile Surgery. Med J Cairo Univ. 2018;86(6):1399-406. doi:10.21608/mjcu.2018.56341

8. Canakci E, Yagan O, Tas N, Mutlu T, Cirakoglu A, Benli E. Comparison of Preventive Analgesia Techniques in Circumcision Cases: Dorsal Penile Nerve Block, Caudal Block, or Subcutaneous Morphine? J Pakistan Med Assoc. 2017;67(2):159-65.

9. Kundra P, Yuvaraj K. Hypospadias surgery and locoregional anesthesia. Pediatr Anesth. 2013;23(6):567-568. doi:10.1111/pan.12179 